\title{
KEPUASAN KERJA MEMEDIASI PENGARUH PERSON- ORGANIZATION FIT TERHADAP KOMITMEN ORGANISASIONAL KARYAWAN BBPOM DENPASAR
}

\author{
Gusti Ayu Krisna ${ }^{1}$ \\ I Gusti Ayu Dewi Adnyani ${ }^{2}$ \\ ${ }^{1,2}$ Fakultas Ekonomi dan Bisnis Universitas Udayana (Unud), Bali, Indonesia \\ email: gustiayutrisna70@gmail.com
}

\begin{abstract}
ABSTRAK
Penelitian ini dilakukan pada Balai Besar Pengawas Obat dan Makan di Denpasar dengan melibatkan 99 responden dengan teknik pengumpulan sampel total. Pengumpulan data menggunakan kuesioner dan dianalisis dengan analisis jalur. Hasil penelitian menemukan Person-Organization Fit berpengaruh positif dan signifikan terhadap komitmen organisasional. Person-Organization Fit berpengaruh positif signifikan terhadap Kepuasan Kerja. Kepuasan kerja berpengaruh positif dan signifikan terhadap Komitmen Organisasional. Kepuasan Kerja mampu secara positif memediasi pengaruh PersonOrganization Fit terhadap Komitmen Organisasional. Hasil penelitian ini memberikan sebuah implikasi kepada pihak Balai Besar Pengawas Obat dan Makanan mengenai Person-Organization Fit tidak sesuai dan Kepuasaan Kerja yang rendah secara nyata dapat menurunkan Komitmen Organisasional, ketika Person-Organization Fit sesuai maka dapat meningkatkan Kepuasaan Kerja yang dirasakan oleh karyawan menjadi semakin kuat sehingga berpotensi meningkatkan Komitmen Organisasional.
\end{abstract}

Kata kunci : person-organization fit, kepuasan kerja, komitmen organisasional

\begin{abstract}
This research was conducted at the Center for Drug and Food Control Denpasar with 99 respondents using saturated sampling. Data collection using a questionnaire and analyzed by path analysis. The results shows Person-Organization Fit has a positive and significant effect on organizational commitment. Person-Organization Fit has a significant positive effect on Job Satisfaction. Job satisfaction has a positive and significant effect on Organizational Commitment. Job Satisfaction is able to positively mediate the influence of Person-Organization Fit on Organizational Commitment. The implication regarding unsuitable Person-Organization Fit and low Job Satisfaction which can significantly reduce Organizational Commitment, when Person-Organization Fit is appropriate, it can increase the Job Satisfaction felt by employee so that it has the potential to increase Organizational Commitment.

Keywords: person-organization fit, job satisfaction, organizational commitment
\end{abstract}




\section{PENDAHULUAN}

Perkembangan lingkungan organisasi yang berkembang secara global menimbulkan tantangan untuk mencapai tujuan dan menjadi lebih sukses dari organisasi lain. Christian (2015) menyatakan apabila berkembang ke arah yang lebih baik, maka karyawan dapat mengarahkan perusahaan untuk mencapai kemajuan. Ditengah lingkungan yang terus berubah dan kondisi yang mengalami gejolak yang tak menentu persaingan antar organisasi menjadi tidak terelakan. Sebuah organisasi juga ditantang untuk mengkaji ulang kondisi sumber daya atau input yang dimilikinya untuk menyusun langkah pengembangan.

Sumber daya manusia merupakan aset penting dalam suatu organisasi, karena merupakan sumber yang mengendalikan organisasi serta mempertahankan dan mengembangkan organisasi dalam menghadapi berbagai tuntutan zaman. Oleh karena itu diperlukan sumber daya manusia yang memiliki komitmen terhadap organisasi untuk merujuk kepada keberpihakan dan kesetiaan karyawan kepada perusahaan dan tujuan-tujuan perusahaan (Nguyen \& Borteyrou, 2016).

Komitmen Organisasional merupakan kondisi dalam diri seseorang yang mencirikan hubungan karyawan dengan perusahaan, lingkungannya dan mempunyai hubungan bagi keputusan untuk melanjutkan atau berhenti dari keanggotaan organisai, tanpa komitmen, karyawan tidak memiliki usaha maksimal dalam meningkatkan kompetensi serta rendahnya motivasi dalam mencapai tujuan organisasi. Bangun et al. (2017) menyebutkan kesesuaian nilai individu dengan nilai organisasi yang tinggi akan dapat meningkatkan komitmen organisasional karyawan. Komitmen karyawan terhadap organisasinya yang dapat memberikan dampak positif pada keberlangsungan organisasi, sehingga kunci utama untuk mempertahankan dan meningkatkan komitmen organisasional adalah dengan menggali kesesuaian nilai individu dengan nilai organisasinya. Tantangan terbesar yang dihadapai perusahaan adalah menarik, menahan dan mengembangkan karyawan. Salah satu cara untuk menghadapi tantangan ini adalah dengan memastikan kesesuaian antara nilai-nilai organisasi dengan nilainilai karyawan, pemahaman terhadap person-organization fit dapat membantu perusahaan untuk memilih para karyawan dengan nilai dan keyakinan yang sesuai dengan organisasi dan membentuk pengalaman-pengalaman yang dapat memperkuat kesesuaian tersebut. Person - organization fit yang tinggi akan membawa dampak pada tingginya komitmen organisasional. Persepsi terhadap esensi dari konsep mengenai kesesuaian adalah apabila sebuah kecocokan adalah bagus, maka tentu akan membuat sebuah kepuasan kerja yang efektif, tetapi sebaliknya dengan kesamaan atau kesesuaian yang kurang baik juga akan menghasilkan kerja yang tidak positif.

Kepuasan kerja pada dasarnya bersifat individual. Setiap individu akan memiliki tingkat kepuasan yang berbeda sesuai dengan penilaian pada dirinya (Agustiningsih et al., 2016). Semakin banyak aspek dalam pekerjaan yang sesuai dengan niat dan keinginannya, maka semakin tinggi kinerja untuk mencapai mencapai tingkat kepuasan yang diinginkan. Kepuasan kerja adalah perasaan positif tentang seseorang merupakan hasil dari evaluasi karakteristik pekerjaannya (Bin Shmailan, 2016). Hanaysha \& Tahir (2016) menyatakan bahwa salah satu masalah terpenting dalam manajemen sumber manusia dalam organisasi adalah 
menciptakan kepuasan dalam pekerjaan karyawan, salah satu faktor yang mendukung kepuasan kerja karyawan adalah person-organization fit. Penyesuaian person-organization fit terhadap organisasi berdampak pada kepuasan. Semakin banyak kesesuaian dalam pekerjaan yang sama dengan keinginan individu, maka semakin tinggi tingkat kepuasan yang dirasakan (Astakhova, 2016)

Menurut Indrawati et al. (2017) kepuasan kerja memiliki pengaruh positif signifikan terhadap komitmen organisasional. Semakin terpuaskan pegawai dalam bekerja, maka semakin enggan dirinya untuk meninggalkan organisasi, dan selalu berkeinginan untuk melakukan hal yang terbaik bagi organisasi. Jika karyawan merasa puas dengan pekerjaannya maka dapat mendorong karyawan tersebut untuk meningkatkan produktifitas perusahaan serta membuat karyawan tetap bertahan di perusahaan (Saputra \& Wibawa, 2018)

Kulachai \& Amaraphibal (2017) menyebutkan salah satu kunci keberhasilan organisasi di era globalisasi saat ini adalah adanya komitmen dalam diri setiap individu dengan memiliki kesesuaian nilai individu dengan nilai organisasi sehingga secara sinergis mampu berkontribusi positif, baik dalam perencanaan maupun dalam proses pengimplementasian tugas dan tanggung jawab sebagai karyawan untuk mencapai visi, misi dan tujuan organisasi agar terciptanya kepuasan kerja karyawan dalam perusahaan

Peran Balai Besar Pengawas Obat dan Makanan (BBPOM) di Denpasar sebagai salah satu Unit Pelaksana Teknis Badan POM RI Sesuai dengan Keputusan Kepala Badan POM RI Nomor 05018/SK/KBPOM tahun 2001 tentang Organisasi dan Tata Kerja Unit Pelaksana Teknis di lingkungan Badan POM, yang kemudian diperbaharui dengan Surat Keputusan Kepala Badan POM Nomor HK.00.05.21.4232 tahun 2004, mempunyai tugas melaksanakan kebijakan di bidang pengawasan produk terapetik, narkotika, psikotropika dan zat adiktif lain, obat tradisional, kosmetik, produk komplimen, produk pangan dan bahan berbahaya. Dalam rangka pencapain Visi dan Misi Organisasi menuntut sejumlah persyaratan, diantaranya memiliki kualifikasi pendidikan profesi dan kompetensi keilmuan, memiliki kemampuan berkomunikasi yang baik untuk berkoordinasi dengan stakeholder (lintas sektor terkait), mempunyai jiwa kreatif dan produktif, mempunyai etos kerja, dan komitmen yang tinggi terhadap profesinya serta selalu melakukan pengembangan diri secara terus menerus.

Tabel 1.

Hasil Prasurvei

\begin{tabular}{lllllll}
\hline No. & Pernyataan & STS & TS & CS & S & SS \\
\hline 1 & Saya secara emosional terikat terhadap organisasi & 0 & 3 & 1 & 1 & 0 \\
2 & $\begin{array}{l}\text { Saya belum mendapatkan manfaat seperti yang saya dapatkan } \\
\text { jika meninggalkan organisasi }\end{array}$ & 0 & 3 & 1 & 1 & 0 \\
$3 \quad$ Saya loyal dengan organisasi & 0 & 4 & 1 & 0 & 0 \\
\hline \multicolumn{2}{l}{ Sumber: Data primer, 2020 } & & & &
\end{tabular}

Dari hasil wawancara dengan Kepala Sub Bagian Tata Usaha dan Hasil prasurvei karyawan Balai Besar Pengawas Obat dan Makanan di Denpasar, 
ditemui indikasi permasalahan yang terkait dengan komitmen organisasional. Hal tersebut banyaknya karyawan Balai Besar Pengawas Obat dan Makanan di Denpasar menjawab tidak setuju atas pernyataan yang diberikan. Hasil prasurvei menunjukan bahwa 4 dari 5 orang karyawan memiliki loyalitas yang rendah yang berimplikasi langsung terhadap pencapaian tujuan organisasi mempengaruhi komitmen bagi karyawan sebab akan menghambat pencapaian kesuksesan bagi karyawan atas kesediaan waktu yang kurang efektif. Penelitian yang dilakukan Jin et al. (2018) menemukan bahwa Person-organization fit tidak berpengaruh signifikan dan negatif terhadap komitmen organisasional. Hasil penelitian tersebut memiliki perbedaan dengan penelitian terdahulu yang dilakukan Aussy. \& Sudarma (2017) dan Rumangkit. \& Maryati (2017) dalam penelitiannya bahwa Person-Organization Fit berpengaruh positif dan signifikan terhadap Komitmen Organisasional. Melihat adanya permasalahan yang muncul terkait komitmen organisasional, serta hasil terdahulu yang menunjukan hasil bertolak belakang, maka permasalahan ini layak di teliti untuk mengetahui bagaimana peran mediasi kepuasan kerja pada pengaruh person-organization fit terhadap komitmen organisasional.

Grand Theory yang mendasari penelitian ini adalah Teori pertukaran sosial. Alasan penggunaan teori pertukaran sosial sebagai teori dasar (grand theory) dalam penelitian ini dikarenakan teori ini mendasari segala permasalahan yang ditemui pada Balai Besar Pengawas Obat dan Makanan di Denpasar terkait adanya hubungan interaksi timbal balik antara variabel bebas person-organization fit $(\mathrm{X})$, variabel mediasi kepuasan kerja $(\mathrm{Z})$ dengan variabel terikat komitmen organisasional (Y). Jika nilai organisasi sesuai dengan nilai individu, maka komitmen organisasional pada karyawan juga akan meningkat. Selain itu adanya kepuasan kerja juga memiliki peran yakni semakin puas karyawan dengan perusahaannya, maka semakin tinggi komitmen organisasional yang dimiliki karyawan tersebut. Adapun kepuasan kerja yang semakin besar pada perusahaan dengan kesesuaian nilai individu dan kesesuaian nilai organisasi yang dimiliki karyawan dapat menunjukkan peningkatan komitmen organisasional pada karyawan dalam organisasi. Variabel tersebut saling berkaitan satu sama lain sehingga dapat disimpulkan adanya peristiwa pertukaran sosial yang terjadi antara karyawan dengan organisasi.

Person-Organization Fit yang tinggi akan dapat meningkatkan komitmen organisasional karyawan. Apabila individu telah bertekad dengan mengikuti objektifitas dan nilai yang dimiliki oleh organisasi, maka hal ini secara tersirat menunjukkan adanya hubungan nilai person-organization fit dan komitmen organisasional. Menurut Collen (2019) menyatakan bahwa menganalisis personorganization fit, kekuatan identitas organisasi, dan prestise organisasi yang dirasakan orang berpengaruh positif dan signifikan pada komitmen organisasi dan kinerja kontekstual. Aussy. \& Sudarma (2017) dalam penelitiannya menunjukan bahwa Person-Organization Fit berpengaruh positif dan signifikan terhadap Komitmen Organisassional. Rumangkit. \& Maryati (2017) menyatakan dalam penelitiannya bahwa person-organization fit berpengaruh positif dan signifikan terhadap komitmen organisasional. Astakhova (2016) dalam penelitiannya menguji saling ketergantungan antara kecocokan person-supervisor dan person- 
organization fit dan hubungannya dengan komitmen organisasi. Di kedua negara, kecocokan person-organization fit yang dirasakan secara positif dan signifikan terhadap komitmen organisasi melalui nilai-nilai kolektif. Hubungan antara persepsi kesesuaian person-supervisor dan komitmen organisasi lebih kuat di Jepang daripada di AS, sedangkan kekuatan hubungan antara persepsi kesesuaian person-organization fit dan komitmen organisasi tidak berbeda di kedua negara. Khaola. \& Sebotsa (2015) yang menggambarkan bagaimana dalam penelitiannya menyebutkan bahwa person-organization fit telah memperoleh hasil yang signifikan dan bernilai positif bila dihubungankan dengan organizational commitment.

$\mathrm{H}_{1}$ : Person-Organization Fit Berpengaruh Positif dan Signifikan Terhadap Komitmen Organisasional

Person-Organization Fit berupa adanya kesesuaian antara nilai-nilai dalam visi, misi organisasi dengan nilai-nilai pada diri individu, perasaan nyaman dengan rekan kerja, kesesuaian karakteristik organisasi dengan pegawai berupa pemberian pelayanan yang sesuai dengan standar kerja mampu meningkatkan kepuasan kerja. Sari \& Helmy (2020) menyatakan bahwa person-organization fit memiliki pengaruh positif dan signifikan terhadap kepuasan kerja. Dengan adanya person-organization fit maka akan terciptanya kepuasan kerja yang tinggi. Gul et al. (2018) dalam penelitiannya menunjukan hubungan positif yang signifikan antara Person-Organization Fit dengan kepuasan kerja. Hasil penelitian Rumangkit. \& Maryati (2017) menyatakan bahwa person-organization fit berpengaruh positif dan signifikan terhadap kepuasan kerja. Risman et al. (2016) juga menunjukan bahwa person-organization fit berpengaruh positif dan signifikan terkait dengan kepuasan kerja. Dalam penelitian Chen et al. (2016) menyatakan bahwa person-organization fit dapat mempengaruhi kepuasan kerja secara positif dan signifikan. Untuk meningkatkan hubungan antara personorganization fit dan kepuasan kerja karyawan melalui dukungan supervisor, supervisor harus mengembangkan bentuk timbal balik yang positif dengan membantu karyawan untuk memecahkan masalah nyata yang mereka hadapi

$\mathrm{H}_{2}$ : Person-Organization Fit Berpengaruh Positif dan Signifikan Terhadap Kepuasan Kerja

Kepuasan kerja adalah mengenai pekerjaan yang dilakukannya menyenangkan atau tidak menyenangkan terhadap pekerjaannya, merasakan puas dalam bekerja maka dapat mendorong untuk meningkatkan produktifitas perusahaan serta memperkuat komitmen organisasional. Rumangkit. \& Maryati (2017) mengatakan kepuasan kerja berpengaruh positif dan signifikan terhadap komitmen organisasional. Kepuasan kerja merupakan sikap umum seseorang dalam menghadapi pekerjaannya. Seseorang yang tinggi kepuasan kerjanya memiliki sikap positif terhadap pekerjaannya, sedangkan seseorang yang tidak memperoleh kepuasan didalam pekerjaannya memiliki sikap yang negatif terhadap pekerjaannya. Dwiki \& Riana (2018) mengatakan bahwa kepuasan kerja berpengaruh positif signifikan terhadap komitmen organisasi. Ariawan \& Sriathi (2018) mengatakan bahwa kepuasan kerja berpengaruh positif dan signifikan terhadap komitmen organisasional. Rumangkit. \& Maryati (2017) menyatakan bahwa kepuasan kerja berpengaruh positif dan signifikan terhadap komitmen 
organisasional. Rosita \& Yuniati (2016), Eliyana \& Ma (2019), Renyut et al. (2017) mengatakan kepuasan kerja berpengaruh positif dan signifikan terhadap komitmen organisasi

$\mathrm{H}_{3}$ : Kepuasan Kerja Berpengaruh Positif dan Signifikan Terhadap Komitmen Organisasional

Kesesuaian antara nilai individu dengan nilai organisasi menjadi dasar kepuasan kerja, dan komitmen karyawan terhadap organisasi. Hal itu menunjukan bahwa seseorang yang memiliki kesesuaian individu dengan organisasi tinggi maka akan meningkatkan kepuasan kerja sehingga akan berdampak pada tetap bertahannya karyawan pada organisasi. Sari \& Helmy (2020) menyatakan bahwa kepuasan kerja dapat memediasi pada pengaruh person-organization fit dengan komitmen organisasional. Rumangkit. \& Maryati (2017) menyatakan bahwa kepuasaan kerja memediasi pengaruh person-organization fit pada komitmen organisasional, person-organization fit yang tinggi akan memicu peningkatan kepuasan kerja karyawan sehingga mampu berperan terhadap peningkatan komitmen organisasional. Ren. \& Hamann (2015) menyatakan bahwa ketika terdapat kesesuaian nilai antara individu dan organisasi, maka individu akan memiliki rasa kebersamaan mencapai tujuan bersama. Ketika tujuan itu harus dicapai, individu akan mengeluarkan segenap pengetahuan, kemampuan, dan keahliannya.

$\mathrm{H}_{4}$ : Mediasi Kepuasan Kerja Berpengaruh Pada Person-Organization Fit Terhadap Komitmen Organisasional

\section{METODE PENELITIAN}

Desain Penelitian yang digunakan adalah penelitian yang bersifat kuantitatif yang secara spesifik adalah asosiatif kausalitas. Penelitian ini merupakan penelitian yang dalam pengujian untuk mengetahui peran mediasi Kepuasan Kerja pada pengaruh Person-Organization Fit terhadap Komitmen Organisasional. Penelitian dilakukan di Balai Besar Pengawas Obat dan Makanan di Denpasar. Adapun alasan yang melatarbelakangi melakukan penelitian Balai Besar Pengawas Obat dan Makanan di Denpasar karena adanya indikasi rendahnya komitmen organisasional dalam pencapaian Visi dan Misi Badan Pegawas Obat dan Makanan RI harus didukung oleh sumber daya manusia yang memiliki komitmen organisasional serta integritas yang tinggi sesuai dengan nilai individu dan nilai yang dianut organisasi serta organisasi harus memiliki standar kebijakan dan aturan yang jelas sehingga dalam pelaksanaan tugas memberikan kepuasan kerja.

Obyek dari penelitian ini adalah Komitmen Organisasional, PersonOrganization Fit dan Kepuasan Kerja. Variabel endogen pada penelitian ini adalah Komitmen Organisasional (Y). Variabel eksogen pada penelitian ini adalah Person-Organization Fit (X). Variabel mediasi pada penelitian ini adalah Kepuasan Kerja (Z). Sumber primer adalah responden atau karyawan Balai Besar Pengawas Obat dan Makanan di Denpasar. Sumber sekunder adalah sumber yang sudah dalam bentuk jadi atau dapat dikatakan sumber yang sudah tersedia pada Balai Besar Pengawas Obat dan Makanan di Denpasar. Instrumen penelitian 
berupa kuesioner, yang terdiri atas pertanyaan tertutup serta pertanyaan terbuka. Pernyataan kuesioner ini diukur dengan menggunakan skala Likert dengan skala 1 sampai 5. Populasi dalam penelitian ini adalah seluruh karyawan Balai Besar Pengawas Obat dan Makanan di Denpasar sebanyak 100 orang.

Populasi dalam penelitian ini adalah seluruh karyawan Balai Besar Pengawas Obat dan Makanan di Denpasar. Besarnya jumlah sampel yang didapat adalah 99 orang, diluar kepala balai, maka metode penentuan sampel yang dilakukan adalah dengan menggunakan sampling total yaitu teknik dengan cara mengambil seluruh anggota populasi dijadikan sebagai sampel. Metode ini dipilih karena mengingat populasi pada penelitian ini masih tergolong sedikit dan dibawah 100 orang, sehingga seluruh anggota populasi dapat dijadikan sebagai sampel dalam penelitian ini. Dalam melakukan analisis terhadap penelitian ini, diperlukan sejumlah data yang relevan dengan permasalahan dan data tersebut yang merupakan bukti objektivitas penelitian. Adapun metode pengumpulan data yang digunakan adalah wawancara dan kuesioner. Teknik analisis data yang digunakan pada penelitian ini adalah teknik analisis jalur (path analysis).

\section{HASIL DAN PEMBAHASAN}

Data karakteristik responden adalah data responden yang dikumpulkan untuk mengetahui profil responden penelitian. Berdasarkan hasil penelitian yang dilakukan terhadap Karyawan Balai Besar Pengawas Obat dan Makanan Di Denpasar dapat diketahui karakteristik respondennya meliputi jenis kelamin, usia, dan masa kerja yang dijelaskan pada Tabel 2.

Tabel 2.

Karakteristik Responden

\begin{tabular}{|c|c|c|c|c|}
\hline No & Variabel & Klasifikasi & Jumlah (orang) & $\begin{array}{l}\text { Persentase } \\
(\%)\end{array}$ \\
\hline \multirow{3}{*}{1} & \multirow{2}{*}{ Jenis Kelamin } & Laki - Laki & 29 & 29.29 \\
\hline & & Perempuan & 70 & 70.70 \\
\hline & \multirow{2}{*}{ Jumlah } & & 99 & 100 \\
\hline \multirow{4}{*}{2} & & 20-30 Tahun & 44 & 44.44 \\
\hline & \multirow{3}{*}{ Usia } & 31-40 Tahun & 41 & 41.41 \\
\hline & & 41-50 Tahun & 10 & 10.10 \\
\hline & & $>50$ Tahun & 4 & 4.04 \\
\hline \multirow{6}{*}{3} & \multirow[t]{2}{*}{ Jumlah } & & 99 & 100 \\
\hline & & SMA/SMK & 12 & 12.12 \\
\hline & \multirow[t]{4}{*}{ Tingkat pendidikan } & Diploma & 5 & 5.05 \\
\hline & & $\mathrm{S} 1$ & 44 & 44.44 \\
\hline & & Apoteker & 26 & 26.26 \\
\hline & & $\mathrm{S} 2$ & 12 & 12.12 \\
\hline \multirow{5}{*}{4} & \multirow[t]{2}{*}{ Jumlah } & & 99 & 100 \\
\hline & & $<10$ Tahun & 42 & 42.42 \\
\hline & \multirow[t]{2}{*}{ Masa kerja } & 10-20 Tahun & 40 & 40.40 \\
\hline & & >20Tahun & 17 & 17.17 \\
\hline & Jumlah & & 99 & 100 \\
\hline
\end{tabular}

Sumber: Data diolah pada Tahun 2020 
Berdasarkan Tabel 2, dapat di lihat Karyawan Balai Besar Pengawas Obat dan Makanan Di Denpasar yang di jadikan sampel sebanyak 99 orang. Jika di lihat dari jenis kelamin, perempuan mendominasi dalam penelitian ini dengan presentase sebesar 70,70 persen, kaum perempuan lebih teliti dan spesifik dalam meneliti sesuatu. Jika di lihat dari usia, yang memiliki usia 20-30 tahun mendominasi dengan presentase sebesar 44,44 persen, yang artinya kelompok usia produktif. Faktor usia seorang pegawai yang produktif dapat menunjang kegiatan organisasi dalam menghasilkan organisasi yang berkualitas, karena dengan umur produktif yang dimiliki akan berkorelasi di dalam pencapaian tujuan organisasi tersebut.

Dilihat dari pendidikan, yang memiliki pendidikan S1 mendominasi dengan presentase sebesar 44,44 persen, yang artinya dianggap sudah mampu serta memadai untuk menjadi karyawan yang memiliki kompetensi untuk mencapai tujuan organisasi. Dilihat dari masa kerja responden yang memiliki masa kerja $<10$ tahun mendominasi dengan persentase sebesar 42,42 persen, yang artinya bahwa karyawan yang bekerja pada Balai Besar Pengawas Obat dan Makan di Denpasar sebesar 42,42 persen cenderung memiliki sikap loyalitas yang tinggi pada organisasi.

Tabel 3.

Rekapitulasi Hasil Uji Validitas Instrumen Penelitian

\begin{tabular}{|c|c|c|c|}
\hline No & Variabel & Instrumen & Pearson Correlation \\
\hline \multirow[t]{6}{*}{1} & Komitmen Organisasional (Y) & Y1 & 0,960 \\
\hline & & $\mathrm{Y} 2$ & 0,920 \\
\hline & & Y3 & 0,976 \\
\hline & & Y4 & 0,939 \\
\hline & & Y5 & 0,969 \\
\hline & & Y6 & 0,882 \\
\hline \multirow[t]{4}{*}{2} & Person-Organization Fit $(\mathrm{X})$ & $\mathrm{X} 1$ & 0,956 \\
\hline & & $\mathrm{X} 2$ & 0,940 \\
\hline & & $\mathrm{X} 3$ & 0,906 \\
\hline & & $\mathrm{X} 4$ & 0,965 \\
\hline \multirow[t]{10}{*}{3} & Kepuasaan Kerja $(\mathrm{Z})$ & $\mathrm{Z} 1$ & 0,850 \\
\hline & & $\mathrm{Z} 2$ & 0,892 \\
\hline & & $\mathrm{Z} 3$ & 0,861 \\
\hline & & $\mathrm{Z} 4$ & 0,917 \\
\hline & & $\mathrm{Z} 5$ & 0,890 \\
\hline & & Z6 & 0,882 \\
\hline & & $\mathrm{Z7}$ & 0,872 \\
\hline & & Z8 & 0,876 \\
\hline & & Z9 & 0,897 \\
\hline & & $\mathrm{Z} 10$ & 0,882 \\
\hline
\end{tabular}

Sumber: Data Primer, (data diolah) 2020

Tabel 3. menunjukkan seluruh instrumen variabel penelitian telah memenuhi syarat uji validitas yang dimana nilai skor total Pearson Correlation masing-masing instrumen berada diatas 0,30 , maka instrumen layak digunakan menjadi alat ukur variabel-variabel tersebut. 
Tabel 4.

Rekapitulasi Hasil Uji Reliabilitas Instrumen Penleitian

\begin{tabular}{lll}
\hline No. & Variabel & Cronbach's Alpha \\
\hline 1. & Komitmen Organisasional $(\mathrm{Y})$ & 0,974 \\
2. & Person-Organization Fit $(\mathrm{X})$ & 0,958 \\
3. & Kepuasaan Kerja $\quad(\mathrm{Z})$ & 0,967 \\
\hline
\end{tabular}

Sumber: Data Primer, (data diolah) 2020

Tabel 4. ditampilkan uji reliabilitas pada masing-masing variabel berada pada titik diatas 0,60 yang ditunjukkan pada hasil Cronbach's Alpha, maka dapat dikatakan seluruh instrumen telah memenuhi syarat reliabilitas.

Tabel 5.

Deskripsi Jawaban Responden Terhadap Komitmen Organisasional

\begin{tabular}{|c|c|c|c|c|c|c|c|c|c|}
\hline \multirow[t]{2}{*}{ No } & \multirow[t]{2}{*}{ Pernyataan } & \multicolumn{5}{|c|}{$\begin{array}{l}\text { Proporsi Jawaban } \\
\text { Responden } \\
\text { (orang) }\end{array}$} & \multirow[t]{2}{*}{ Jumlah } & \multirow[t]{2}{*}{$\begin{array}{l}\text { Rata- } \\
\text { rata }\end{array}$} & \multirow[t]{2}{*}{ Kriteria } \\
\hline & & 1 & 2 & 3 & 4 & 5 & & & \\
\hline 1 & $\begin{array}{l}\text { Saya secara emosional } \\
\text { terikat terhadap organisasi }\end{array}$ & 10 & 20 & 12 & 33 & 24 & 338 & 3.41 & Tinggi \\
\hline 2 & $\begin{array}{l}\text { Saya merasa menjadi } \\
\text { bagian dari organisasi }\end{array}$ & 8 & 22 & 20 & 27 & 22 & 330 & 3.33 & Sedang \\
\hline 3 & $\begin{array}{l}\text { Saya belum mendapatkan } \\
\text { manfaat seperti yang saya } \\
\text { dapatkan jika meninggalkan } \\
\text { organisasi }\end{array}$ & 8 & 18 & 18 & 33 & 22 & 340 & 3.43 & Tinggi \\
\hline 4 & $\begin{array}{l}\text { Saya akan mengalami } \\
\text { kerugian jika meninggalkan } \\
\text { organisasi }\end{array}$ & 4 & 20 & 20 & 31 & 24 & 348 & 3.52 & Tinggi \\
\hline 5 & $\begin{array}{l}\text { Saya loyal terhadap } \\
\text { organisasi }\end{array}$ & 8 & 22 & 16 & 31 & 22 & 334 & 3.37 & Sedang \\
\hline 6 & $\begin{array}{l}\text { Saya berkewajiban bertahan } \\
\text { dalam organisasi }\end{array}$ & 6 & 24 & 24 & 24 & 21 & 327 & 3.30 & Sedang \\
\hline \multicolumn{2}{|c|}{ Rata-rata } & & & & & & & 3,40 & Sedang \\
\hline
\end{tabular}

Sumber: Data Primer, (data diolah) 2020

Berdasarkan Tabel 5. diketahui persepsi responden mengenai variabel Komitmen Organisasional yang memiliki rata-rata terendah adalah pernyataan "Saya berkewajiban bertahan dalam organisasi", diperoleh nilai rata-rata sebesar 3,30 yang masuk kriteria sedang, tetapi memiliki nilai rata-rata yang rendah dibandingkan dengan pernyataan yang lainnya ini berarti secara umum responden tidak berkewajiban bertahan dalam organisasi.

Variabel Komitmen Organisasional yang memiliki rata-rata tertinggi adalah pernyataan "Saya akan mengalami kerugian jika meninggalkan organisasi", diperoleh nilai rata-rata sebesar 3,52 yang masuk kriteria tinggi, ini berarti secara umum responden merasa akan mengalami kerugian jika meninggalkan organisasi. Total rata-rata jawaban responden terhadap Komitmen Organisasional sebesar 3,40 dengan kriteria sedang, ini berarti tingkat komitmen organisasional pada karyawan Balai Besar Pengawas Obat dan Makanan di Denpasar berada pada posisi sedang. 
Variabel Person-Organization Fit pada penelitian ini merupakan variabel bebas. Variabel Person-Organization Fit yang disimbolkan dengan X serta diukur dengan menggunakan 4 pernyataan yang ditanggapi menggunakan 5 poin Skala Likert. Berdasarkan Tabel 6 diketahui persepsi responden mengenai variabel Person-Organization Fit memiliki rata-rata terendah adalah pernyataan "Tujuan bekerja saya sesuai dengan tujuan organisasi.", diperoleh nilai rata-rata sebesar 3,23 yang masuk kriteria cukup baik, tetapi memiliki nilai rata-rata yang rendah dibandingkan dengan pernyataan yang lainnya ini berarti secara umum responden menganggap tujuan bekerja belum sesuai dengan tujuan organisasi.

Tabel 6.

Deskripsi Jawaban Responden Terhadap Person-Organization Fit

\begin{tabular}{|c|c|c|c|c|c|c|c|c|c|}
\hline \multirow[t]{2}{*}{ No } & \multirow[t]{2}{*}{ Pernyataan } & \multicolumn{5}{|c|}{$\begin{array}{c}\text { Proporsi Jawaban } \\
\text { Responden } \\
\text { (orang) }\end{array}$} & \multirow[t]{2}{*}{ Jumlah } & \multirow[t]{2}{*}{$\begin{array}{l}\text { Rata- } \\
\text { rata }\end{array}$} & \multirow[t]{2}{*}{ Kriteria } \\
\hline & & 1 & 2 & 3 & 4 & 5 & & & \\
\hline 1 & $\begin{array}{l}\text { Saya merasa nilai-nilai } \\
\text { pribadi saya sesuai dengan } \\
\text { tempat saya bekerja. }\end{array}$ & 0 & 28 & 12 & 45 & 14 & 342 & 3.45 & Baik \\
\hline 2 & $\begin{array}{l}\text { Tujuan bekerja saya sesuai } \\
\text { dengan tujuan organisasi. } \\
\text { Kebutuhan sava sesuai }\end{array}$ & 4 & 24 & 24 & 39 & 8 & 320 & 3.23 & $\begin{array}{l}\text { Cukup } \\
\text { Baik }\end{array}$ \\
\hline 3 & $\begin{array}{l}\text { dengan apa yang dimiliki } \\
\text { oleh organisasi. }\end{array}$ & 0 & 12 & 36 & 31 & 20 & 356 & 3.60 & Baik \\
\hline 4 & $\begin{array}{l}\text { Karakteristik kepribadian } \\
\text { saya sesuai dengan } \\
\text { lingkungan internal } \\
\text { organisasi }\end{array}$ & 4 & 26 & 14 & 47 & 8 & 326 & 3.29 & $\begin{array}{l}\text { Cukup } \\
\text { Baik }\end{array}$ \\
\hline \multicolumn{2}{|c|}{ Rata-rata } & & & & & & & $\mathbf{3 , 3 9}$ & $\begin{array}{l}\text { Cukup } \\
\text { Baik }\end{array}$ \\
\hline
\end{tabular}

Sumber: Data Primer, (data diolah) 2020

Variabel Person-Organization Fit yang memiliki rata-rata tertinggi adalah pernyataan "Kebutuhan saya sesuai dngan apa yang dimiliki oleh organisasi", diperoleh nilai rata-rata sebesar 3,60 yang masuk kriteria baik, ini berarti secara umum responden merasa kebutuhan mereka sesuai dengan apa yang dimiliki oleh organisasi. Total rata-rata jawaban responden terhadap Person-Organization Fit sebesar 3,39 dengan kriteria cukup baik, ini berarti bahwa tingkat PersonOrganization Fit pada karyawan Balai Besar Pengawas Obat dan Makanan di Denpasar berada pada posisi cukup baik.

Variabel Kepuasaan Kerja pada penelitian ini merupakan variabel mediasi. Variabel Kepuasaan Kerja yang disimbolkan dengan Z serta diukur dengan menggunakan 10 pernyataan yang ditanggapi menggunakan 5 poin Skala Likert. Berdasarkan Tabel 7 diketahui persepsi responden mengenai variabel Kepuasaan Kerja yang memiliki rata-rata terendah adalah pernyataan "Saya memiliki kesempatan promosi sesuai dengan hasil kerja yang baik.", diperoleh nilai ratarata sebesar 3,19 yang masuk kriteria cukup, tetapi memiliki nilai rata-rata yang rendah dibandingkan dengan pernyataan yang lainnya ini berarti secara umum 
responden menganggap belum memiliki kesempatan promosi sesuai dengan hasil kerja yang baik.

Variabel Kepuasaan Kerja yang memiliki rata-rata tertinggi adalah pernyataan "Saya dapat berkomunikasi dengan baik dengan rekan kerja", diperoleh nilai rata-rata sebesar 3,76 yang masuk kriteria baik, ini berarti secara umum responden merasa dapat berkomunikasi dengan baik dengan rekan kerja. Total rata-rata jawaban responden terhadap Kepuasan Kerja sebesar 3,51 dengan kriteria tinggi, ini berarti tingkat kepuasan kerja pada karyawan Balai Besar Pengawas Obat dan Makanan di Denpasar berada pada posisi tinggi.

Tabel 7.

Deskripsi Jawaban Responden Terhadap Kepuasaan Kerja

\begin{tabular}{|c|c|c|c|c|c|c|c|c|c|}
\hline \multirow[t]{2}{*}{ No } & \multirow[t]{2}{*}{ Pernyataan } & \multicolumn{5}{|c|}{$\begin{array}{l}\text { Proporsi Jawaban } \\
\text { Responden } \\
\text { (orang) }\end{array}$} & \multirow[t]{2}{*}{ Jumlah } & \multirow{2}{*}{$\begin{array}{l}\text { Rata- } \\
\text { rata }\end{array}$} & \multirow[t]{2}{*}{ Kriteria } \\
\hline & & 1 & 2 & 3 & 4 & 5 & & & \\
\hline 1 & $\begin{array}{l}\text { Saya dapat bekerja dengan } \\
\text { kemampuan }\end{array}$ & 4 & 18 & 18 & 45 & 14 & 344 & 3.47 & Tinggi \\
\hline 2 & $\begin{array}{l}\text { Saya dapat bekerja dengan } \\
\text { keterampilan }\end{array}$ & 0 & 22 & 28 & 15 & 34 & 358 & 3.62 & Tinggi \\
\hline 3 & $\begin{array}{l}\text { Saya puas atas gaji yang } \\
\text { diberikan sesuai dengan } \\
\text { jasa yang diberikan }\end{array}$ & 0 & 20 & 20 & 31 & 28 & 364 & 3.68 & Tinggi \\
\hline 4 & $\begin{array}{l}\text { Saya memiliki kesempatan } \\
\text { dalam kenaikan gaji }\end{array}$ & 0 & 32 & 14 & 27 & 26 & 344 & 3.47 & Tinggi \\
\hline 5 & $\begin{array}{l}\text { Saya memiliki kesempatan } \\
\text { promosi sesuai dengan } \\
\text { keahlian yang dimiliki }\end{array}$ & 8 & 18 & 18 & 23 & 32 & 350 & 3.54 & Tinggi \\
\hline 6 & $\begin{array}{l}\text { Saya memiliki kesempatan } \\
\text { promosi sesuai dengan hasil } \\
\text { kerja yang baik. } \\
\text { Atasan saya selalu }\end{array}$ & 8 & 26 & 10 & 49 & 6 & 316 & 3.19 & Sedang \\
\hline 7 & $\begin{array}{l}\text { memberikan dukungan } \\
\text { dalam bekerja }\end{array}$ & 0 & 30 & 20 & 19 & 30 & 346 & 3.49 & Tinggi \\
\hline 8 & $\begin{array}{l}\text { Atasan saya selalu bersikap } \\
\text { adil } \\
\text { Sava menvukai }\end{array}$ & 8 & 20 & 16 & 32 & 23 & 339 & 3.42 & Tinggi \\
\hline 9 & $\begin{array}{l}\text { bekerjasama dengan rekan } \\
\text { kerja }\end{array}$ & 2 & 30 & 14 & 27 & 26 & 342 & 3.45 & Tinggi \\
\hline 10 & $\begin{array}{l}\text { Saya dapat berkomunikasi } \\
\text { dengan baik dengan rekan } \\
\text { kerja }\end{array}$ & 0 & 20 & 20 & 23 & 36 & 372 & 3.76 & Tinggi \\
\hline Rat & tta & & & & & & & $\mathbf{3 , 5 1}$ & Tinggi \\
\hline
\end{tabular}

Sumber: Data Primer, (data diolah) 2020 
Tabel 8.

Hasil Analisis Jalur Pada Struktur 1

\begin{tabular}{|c|c|c|c|c|c|}
\hline \multirow[t]{2}{*}{ Model } & \multicolumn{2}{|c|}{ Unstandardized Coefficients } & \multirow{2}{*}{$\begin{array}{l}\begin{array}{l}\text { Standardized } \\
\text { Coefficients }\end{array} \\
\text { Beta } \\
\end{array}$} & \multirow[t]{2}{*}{$\mathbf{T}$} & \multirow[t]{2}{*}{ Sig. } \\
\hline & $\mathbf{B}$ & Std. Error & & & \\
\hline (Constant) & 0.710 & 0.245 & & 2.902 & 0.005 \\
\hline $\begin{array}{l}\text { Person-Organization } \\
\text { Fit }\end{array}$ & 0.825 & 0.069 & 0.770 & 11.891 & 0.000 \\
\hline$: 0,593$ & & & & & \\
\hline
\end{tabular}

Variabel Person-Organization Fit memiliki koefisien sebesar 0,770 berarti Person-Organization Fit memiliki pengaruh positif terhadap Kepuasaan Kerja, ini diartikan apabila Person-Organization Fit meningkat maka Kepuasaan Kerja akan meningkat sebesar 0,770. Pada penelitian ini dihitung pengaruh PersonOrganization Fit dan Kepuasaan Kerja terhadap Komitmen Organisasional melalui program SPSS 21.0 for windows. Berikut ini ditampilkan hasil perhitungan struktur kedua pada Tabel 9.

Tabel 9.

Hasil Analisis Jalur Pada Struktur 2

\begin{tabular}{|c|c|c|c|c|c|}
\hline \multirow{2}{*}{ Model } & \multicolumn{2}{|c|}{$\begin{array}{l}\text { Unstandardized } \\
\text { Coefficients }\end{array}$} & $\begin{array}{l}\text { Standardized } \\
\text { Coefficients }\end{array}$ & $\mathbf{T}$ & \multirow[t]{2}{*}{ Sig. } \\
\hline & $\mathrm{B}$ & Std. Error & Beta & & \\
\hline (Constant) & -0.045 & 0.276 & & -0.162 & 0.872 \\
\hline Person-Organization Fit & 0.690 & 0.117 & 0.566 & 5.875 & 0.000 \\
\hline Kepuasaan Kerja & 0.313 & 0.110 & 0.275 & 2.855 & 0.005 \\
\hline
\end{tabular}

Sumber: Data Primer, (data diolah) 2020

Variabel Person-Organization Fit memiliki koefisien sebesar 0,566 berarti Person-Organization Fit memiliki pengaruh positif terhadap Komitmen Organisasional, ini diartikan apabila Person-Organization Fit meningkat maka Komitmen Organisasional akan meningkat sebesar 0,566. Variabel Kepuasaan Kerja memiliki koefisien sebesar 0,275 berarti Kepuasaan Kerja memiliki pengaruh positif terhadap Komitmen Organisasional, ini diartikan apabila Kepuasaan Kerja meningkat maka Komitmen Organisasional akan meningkat sebesar 0,275.

Pada perhitungan nilai koefisien determinasi total didapatkan sebesar 0,852, maka kesimpulannya adalah 85,2\% variabel Komitmen Organisasional Karyawan Balai Besar Pengawas Obat dan Makanan Di Denpasar dipengaruhi oleh Person-Organization Fit, dan Kepuasaan Kerja, sedangkan sisanya 14,8\% dipengaruhi oleh faktor lain yang tidak dimasukkan dalam model penelitian atau diluar model penelitian. Berdasarkan pemaparan mengenai persamaan struktural maka akan dijelaskan hasil nilai dari perhitungan koefisien jalur yang ditunjukkan melalui nilai standardized coefficient Beta pada masing-masing pengaruh hubungan antar variabel. 
Tabel 10.

Pengaruh Langsung, Pengaruh Tidak Langsung Person-Organization Fit (X), Terhadap Kepuasaan Kerja (Z) dan Komitmen Organisasional (Y).

\begin{tabular}{llll}
\hline Pengaruh variabel & $\begin{array}{l}\text { Pengaruh } \\
\text { langsung }\end{array}$ & $\begin{array}{l}\text { Pengaruh tidak } \\
\text { langsung melalui } Z\end{array}$ & Pengaruh Total \\
\hline $\mathrm{X} \rightarrow \mathrm{Z}$ & 0,770 & & 0,770 \\
$\mathrm{Z} \rightarrow \mathrm{Y}$ & 0,275 & & 0,275 \\
$\mathrm{X} \rightarrow \mathrm{Y}$ & 0,566 & 0,212 & 0,778 \\
\hline
\end{tabular}

Sumber: Data Primer, (data diolah) 2020

Pada Tabel 10 ditampilkan hasil ringkasan nilai masing-masing jalur pengaruh langsung dan tidak langsung antar variabel serta nilai error pada masing-masing persamaan struktural yang dihasilkan melalui teknik analisis jalur.

Pada penelitian yang dilakukan terhadap Karyawan Balai Besar Pengawas Obat dan Makanan Di Denpasar tentang pengaruh Person-Organization Fit terhadap Kepuasaan Kerja, maka didapatkan hasil Person-Organization Fit memiliki pengaruh langsung terhadap Kepuasaan Kerja sebesar 0,770. Pada penelitian yang dilakukan terhadap Karyawan Balai Besar Pengawas Obat dan Makanan Di Denpasar tentang pengaruh Person-Organization Fit terhadap Komitmen Organisasional, maka didapatkan hasil Person-Organization Fit memiliki pengaruh langsung terhadap Komitmen Organisasional sebesar 0,566

Pada penelitian yang dilakukan terhadap Karyawan Balai Besar Pengawas Obat dan Makanan Di Denpasar tentang pengaruh Kepuasaan Kerja terhadap Komitmen Organisasional, maka didapatkan hasil Kepuasaan Kerja memiliki pengaruh langsung terhadap Komitmen Organisasional sebesar 0,275. Pada penelitian yang dilakukan terhadap Karyawan Balai Besar Pengawas Obat dan Makanan Di Denpasar tentang peran Kepuasaan Kerja dalam memediasi pengaruh Person-Organization Fit terhadap Komitmen Organisasional, maka didapatkan hasil bahwa Person-Organization Fit memiliki pengaruh langsung dan tidak langsung melalui Kepuasaan Kerja terhadap Komitmen Organisasional dengan nilai koefisien masing-masing sebesar 0,566 dan 0,212, sehingga besaran pengaruh totalnya adalah 0,778

Tabel 11.

Uji Normalitas (One-Sample Kolmogorov-Smirnov)

\begin{tabular}{ll}
\hline Persamaan & $\begin{array}{l}\text { Asymp. Sig. (2-tailed) } \\
\text { Kolmogorov-Smirnov Z }\end{array}$ \\
\hline Substruktur 1 & 0,115 \\
Substruktur 2 & 0,104 \\
\hline
\end{tabular}

Sumber: Data Primer, (data diolah) 2020

Tabel 11. menunjukkan bahwa besarnya nilai Asymp. Sig. (2-tailed) Kolmogorov-Smirnov adalah sebesar 0,115 dan 0,104. Nilai Asymp. Sig. (2tailed) Kolmogorov-Smirnov tersebut lebih besar dibandingkan dengan nilai alpha sebesar 0,05 maka mengindikasikan bahwa data yang digunakan pada penelitian 
ini terdistribusi normal, sehingga dapat disimpulkan bahwa model memenuhi asumsi normalitas

Tabel 12.

Uji Multikolinieritas (Tolerance dan Variance Inflation Factor)

\begin{tabular}{llll}
\hline \multirow{2}{*}{ Model } & \multicolumn{2}{c}{ Collinearity Statistics } \\
\cline { 2 - 4 } & Person-Organization & 0.407 & VIF \\
\hline \multirow{3}{*}{ Substruktur2 } & Fit & 0.407 & 2.458 \\
& Kepuasan Kerja & & 2.458 \\
\hline Sumber: Data Primer, (data diolah) 2020 &
\end{tabular}

Tabel 12. meunjukkan bahwa tidak terdapat variabel bebas yang memiliki nilai tolerance kurang dari 0,10 dan juga tidak ada variabel bebas yang memiliki nilai VIF lebih dari 10. Maka dari pada itu model regresi bebas dari gejala multikoleniaritas

Tabel 13.

Uji Heteroskedastisitas (Uji Glesjer)

\begin{tabular}{llrr}
\hline Persamaan & Model & T & \multicolumn{2}{c}{ Sig. } \\
\hline Substruktur1 & Person-Organization Fit & 1,385 & 0,169 \\
\multirow{2}{*}{ Substruktur 2 } & Person-Organization Fit & $-0,488$ & 0,627 \\
& Kepuasan Kerja & 1,868 & 0,065 \\
\hline
\end{tabular}

Sumber: Data Primer, (data diolah) 2020

Tabel 13. tersebut menunjukkan bahwa masing-masing model memiliki nilai signifikansi lebih besar dari 5\%. Hal ini menunjukkan bahwa variabel bebas yang digunakan pada penelitian ini tidak berpengaruh secara signifikan terhadap variabel terikatnya yaitu absolute error, maka dari itu, penelitian ini bebas dari gejala heteroskedastisitas.

Berdasarkan hasil Uji Sobel menunjukkan bahwa hasil tabulasi $\mathrm{Z}=$ 2,430>1,96 yang berarti variabel Person-Organization Fit berpengaruh positif dan signifikan terhadap Komitmen Organisasional Karyawan Balai Besar Pengawas Obat dan Makanan Di Denpasar dengan mediasi Kepuasaan Kerja, sehingga Kepuasaan Kerja merupakan variabel mediasi pengaruh antara PersonOrganization Fit terhadap Komitmen Organisasional Karyawan Balai Besar Pengawas Obat dan Makanan Di Denpasar, dimana variabel kepuasan kerja dapat dinyatakan sebagai variabel mediasi sebagian (partial mediation).

Person-Organization Fit yang tinggi akan dapat meningkatkan komitmen organisasional karyawan. Apabila individu telah bertekad dengan mengikuti objektifitas dan nilai yang dimiliki oleh organisasi, maka hal ini secara tersirat menunjukkan adanya hubungan nilai person-organization fit dan komitmen organisasional. Hasil hipotesis dalam penelitian ini menunjukkan bahwa PersonOrganization Fit berpengaruh positif dan signifikan terhadap Komitmen Organisasional dengan kata lain semakin meningkat Person-Organization Fit 
maka Komitmen Organisasional Karyawan Balai Besar Pengawas Obat dan Makanan Di Denpasar.

Hasil penelitian ini sesuai dengan penelitian sebelumnya yang dilakukan oleh Collen (2019) menyatakan bahwa menganalisis person-organization fit, kekuatan identitas organisasi, dan prestise organisasi yang dirasakan orang berpengaruh positif dan signifikan pada komitmen organisasi dan kinerja kontekstual. Aussy. \& Sudarma (2017) dalam penelitiannya menunjukan bahwa Person-Organization Fit berpengaruh positif dan signifikan terhadap Komitmen Organisassional. Rumangkit. \& Maryati (2017) menyatakan dalam penelitiannya bahwa person-organization fit berpengaruh positif dan signifikan terhadap komitmen organisasional. Astakhova (2016) dalam penelitiannya menguji saling ketergantungan antara kecocokan person-supervisor dan person-organization fit dan hubungannya dengan komitmen organisasi. Di kedua negara, kecocokan person-organization fit yang dirasakan secara positif dan signifikan terhadap komitmen organisasi melalui nilai-nilai kolektif. Hubungan antara persepsi kesesuaian person-supervisor dan komitmen organisasi lebih kuat di Jepang daripada di AS, sedangkan kekuatan hubungan antara persepsi kesesuaian personorganization fit dan komitmen organisasi tidak berbeda di kedua negara. Khaola. \& Sebotsa (2015) yang menggambarkan bagaimana dalam penelitiannya menyebutkan bahwa person-organization fit telah memperoleh hasil yang signifikan dan bernilai positif bila dihubungankan dengan organizational commitment

Person-Organization Fit berupa adanya kesesuaian antara nilai-nilai dalam visi, misi organisasi dengan nilai-nilai pada diri individu, perasaan nyaman dengan rekan kerja, kesesuaian karakteristik organisasi dengan pegawai berupa pemberian pelayanan yang sesuai dengan standar kerja mampu meningkatkan kepuasan kerja. Hasil hipotesis dalam penelitian ini menunjukkan bahwa PersonOrganization Fit memiliki pengaruh positif dan signifikan terhadap Kepuasaan Kerja dengan kata lain semakin meningkat Person-Organization Fit Karyawan Balai Besar Pengawas Obat dan Makanan Di Denpasar, maka semakin tinggi tingkat Kepuasaan Kerja Karyawan Balai Besar Pengawas Obat dan Makanan Di Denpasar.

Hasil penelitian ini sesuai dengan penelitian sebelumnya yang dilakukan oleh Sari \& Helmy (2020) menyatakan person-organization fit memiliki pengaruh positif dan signifikan terhadap kepuasan kerja. Dengan adanya personorganization fit maka akan terciptanya kepuasan kerja yang tinggi. Gul et al. (2018) dalam penelitiannya menunjukan hubungan positif yang signifikan antara Person-Organization Fit dengan kepuasan kerja. Hasil penelitian Rumangkit. \& Maryati (2017) menyatakan bahwa person-organization fit berpengaruh positif dan signifikan terhadap kepuasan kerja. Risman et al. (2016) juga menunjukan bahwa person-organization fit berpengaruh positif dan signifikan terkait dengan kepuasan kerja. Dalam penelitian Chen et al. (2016) menyatakan bahwa personorganization fit dapat mempengaruhi kepuasan kerja secara positif dan signifikan.

Kepuasan kerja adalah mengenai pekerjaan yang dilakukannya menyenangkan atau tidak menyenangkan terhadap pekerjaannya, merasakan puas 
dalam bekerja maka dapat mendorong untuk meningkatkan produktifitas perusahaan serta memperkuat komitmen organisasional. Hasil hipotesis dalam penelitian ini menunjukkan bahwa Kepuasaan Kerja memiliki pengaruh positif dan signifikan terhadap Komitmen Organisasional, dengan kata lain apabila Kepuasaan Kerja meningkat maka Komitmen Organisasional Karyawan Balai Besar Pengawas Obat dan Makanan Di Denpasar.

Hasil penelitian ini sesuai dengan penelitian sebelumnya yang dilakukan oleh Rumangkit. \& Maryati (2017) mengatakan bahwa kepuasan kerja berpengaruh positif dan signifikan terhadap komitmen organisasional. Kepuasan kerja merupakan sikap umum seseorang dalam menghadapi pekerjaannya. Seseorang yang tinggi kepuasan kerjanya memiliki sikap positif terhadap pekerjaannya, sedangkan seseorang yang tidak memperoleh kepuasan didalam pekerjaannya memiliki sikap yang negatif terhadap pekerjaannya. Dwiki \& Riana (2018) mengatakan bahwa kepuasan kerja berpengaruh positif signifikan terhadap komitmen organisasi. Ariawan \& Sriathi (2018) mengatakan bahwa kepuasan kerja berpengaruh positif dan signifikan terhadap komitmen organisasional. Rumangkit. \& Maryati (2017) menyatakan bahwa kepuasan kerja berpengaruh positif dan signifikan terhadap komitmen organisasional. Rosita \& Yuniati (2016) mengatakan kepuasan kerja berpengaruh positif dan signifikan terhadap komitmen organisasi.

Kesesuaian antara nilai individu dengan nilai organisasi menjadi dasar kepuasan kerja, dan komitmen karyawan terhadap organisasi. Hal itu menunjukan bahwa seseorang yang memiliki kesesuaian individu dengan organisasi tinggi maka akan meningkatkan kepuasan kerja sehingga akan berdampak pada tetap bertahannya karyawan pada organisasi. Hasil hipotesis dalam penelitian ini menunjukkan bahwa Person-Organization Fit berpengaruh positif dan signifikan terhadap Komitmen Organisasional Karyawan Balai Besar Pengawas Obat dan Makanan Di Denpasar dengan mediasi Kepuasaan Kerja, sehingga Kepuasaan Kerja merupakan variabel mediasi pengaruh antara Person-Organization Fit terhadap Komitmen Organisasional Karyawan Balai Besar Pengawas Obat dan Makanan Di Denpasar, dimana variabel kepuasan kerja dapat dinyatakan sebagai variabel mediasi sebagian (partial mediation).

Hasil penelitian ini sesuai dengan penelitian sebelumnya yang dilakukan oleh Sari \& Helmy (2020) menyatakan kepuasan kerja dapat memediasi pada pengaruh person-organization fit dengan komitmen organisasional. Rumangkit. \& Maryati (2017) menyatakan bahwa kepuasaan kerja memediasi pengaruh personorganization fit pada komitmen organisasional. Person-organization fit yang tinggi akan memicu peningkatan kepuasan kerja karyawan sehingga mampu berperan terhadap peningkatan komitmen organisasional. Ren. \& Hamann (2015) menyatakan bahwa ketika terdapat kesesuaian nilai antara individu dan organisasi, maka individu akan memiliki rasa kebersamaan mencapai tujuan bersama.

Implikasi teoritis dari hasil penelitian ini memberikan bukti pada pengembangan ilmu perilaku organisasi dan ilmu manajemen khususnya mengenai Person-Organization Fit, Kepuasaan Kerja dan Komitmen Organisasional. Secara teoritis penelitian ini juga memberikan pemahaman bahwa Person-Organization Fit tidak sesuai dan Kepuasaan Kerja yang rendah secara 
nyata dapat menurunkan Komitmen Organisasional, ketika Person-Organization Fit sesuai maka dapat meningkatkan Kepuasaan Kerja yang dirasakan oleh karyawan menjadi semakin kuat sehingga berpotensi meningkatkan Komitmen Organisasional. Selain itu hasil penelitian ini Secara praktis dapat menjadi salah satu acuan bagi peneliti lainnnya yang ingin meneliti mengenai PersonOrganization Fit, Kepuasaan Kerja dan Komitmen Organisasional.

Keterbatasan penelitian ini adalah ruang lingkup penelitian hanya mencakup Balai Besar Pengawas Obat dan Makanan di Denpasar sehingga tidak dapat menggambarkan komitmen organisasional secara umum di seluruh Bali. Pandemi covid-19 mempengaruhi pengisian kuesioner yang memerlukan waktu lama, karena responden Balai Besar Pengawas Obat dan Makanan di Denpasar sebagian bekerja dari rumah (work from home) sehingga membuat jadwal pengumpulan semakin terundur dan mempengaruhi jadwal serta target penelitian yang telah ditetapkan. Penelitian ini hanya dilakukan dalam titik waktu tertentu (cross section), sedangkan lingkungan setiap saat berubah (dinamis), sehingga penelitian ini penting untuk dilakukan kembali dimasa mendatang.

\section{SIMPULAN}

Person-Organization Fit berpengaruh positif dan signifikan terhadap Komitmen Organisasional Karyawan Balai Besar Pengawas Obat dan Makanan Di Denpasar. Semakin meningkat Person-Organization Fit semakin tinggi Komitmen Organisasional Karyawan. Person-Organization Fit berpengaruh positif dan signifikan terhadap Kepuasaan Kerja Karyawan Balai Besar Pengawas Obat dan Makanan Di Denpasar. Semakin meningkat Person-Organization Fit semakin tinggi Kepuasan Kerja Karyawan. Kepuasaan Kerja berpengaruh positif dan signifikan terhadap Komitmen Organisasional Karyawan Balai Besar Pengawas Obat dan Makanan Di Denpasar. Semakin tinggi Kepuasan Kerja maka semakin tinggi Komitmen Organisasional karyawan. Kepuasaan Kerja merupakan variabel mediasi pengaruh antara Person-Organization Fit terhadap Komitmen Organisasional Karyawan Balai Besar Pengawas Obat dan Makanan Di Denpasar, dimana variabel kepuasan kerja dapat dinyatakan sebagai variabel mediasi sebagian (partial mediation).

Variabel Komitmen Organisasional yang memiliki nilai rata-rata terendah adalah Saya berkewajiban bertahan dalam organisasi, hal yang harus dilakukan perusahaan memperhatikan keinginan karyawan sesuai dengan kebutuhan pelaksanaan tugas-tugas agar karyawan tersebut merasanya nyaman dan tetap bertahan berada dalam organiasi. Variabel Person-Organization Fit indikator yang memiliki rata-rata terendah adalah Tujuan bekerja saya sesuai dengan tujuan organisasi, yang harus dilakukan oleh perusahaan adalah Pemimpin harus bisa menunjukan memberikan pengertian mengenai tujuan organisasi agar karyawan mengerti dan bisa menyatukan tujuan mereka dengan organisasi. Variabel Kepuasaan Kerja indikator yang memiliki rata-rata terendah adalah Saya memiliki kesempatan promosi sesuai dengan hasil kerja yang baik, hal yang harus dilakukan oleh perusahaan adalah memberikan kesempatan promosi sesuai hasil 
kerja mereka agar mereka merasa senang dan memiliki komitmen terhadap organisasi dimana mereka bekerja karena karyawan sudah merasa di perhatikan.

\section{REFERENSI}

Agustiningsih, H. N., Thoyib, H., \& Noermijiati, N. (2016). The Effect of Remuneration, Job Satisfaction and OCB on the Employee Performance. Sceince Journal of Business and Management, 5(6), 212-222.

Ariawan, P. A. ., \& Sriathi, A. A. A. (2018). Pengaruh stres kerja dan kepuasan kerja terhadap komitmen organisasional PBF. PT Banyumas Denpasar. EJurnal Manajemen, 7(2), 964-992.

Astakhova, M. N. (2016). Explaining the effects of perceived person-supervisor fit and person-organization fit on organizational commitment in the US and Japan. Journal of Business Research, 69(2), 956-963.

Aussy., N. A., \& Sudarma, K. (2017). Pengaruh person organization fit dan personality pada organizational citizenship behavior dengan organizational commitment sebagai variabel intervening. Management Analysis Journal, 6(3), 286-296.

Bangun, O. V, Supartha, I. W. ., \& Subudi. (2017). Pengaruh Person-Job Fit Dan Person-Organization Fit Terhadap Komitmen Organisasional Dan Organizational Citizenship Behavior (OCB). E-Jurnal Ekonomi Dan Bisnis Universitas Udayana, 6(5), 2071-2102.

Bin Shmailan, A. . (2016). The Relationship between Job Satisfaction, Job Performance and Employee Engagement: An Explorative Study. Issues in Business Management and Economics, 4(1), 1-8.

Chen, P., Sparrow, P., \& Cooper, C. (2016). The relationship between personorganization fit and job satisfaction. Journal of Managerial Psychology, 31(5), 946-959.

Christian, L. Y. (2015). Pengaruh Perceived Organizational Support dan Kepemimpinan Situasional terhadap Kepuasan Kerja Karyawan pada Toko Buku Uranus. AGORA, 3(1), 442-449.

Collen, H. Ö. (2019). The Relationships Of Contextual Performance With PersonOrganization Fit, Perceived Organizational Prestige And Organizational Identity Strength: The Mediating Role Of Organizational Commitment. European Journal of Multidisciplinary Studies, 4(2), 28-37.

Dwiki, I. M., \& Riana, I. G. (2018). Peran Kepuasan Kerja Dalam Memediasi Pengaruh Servant Leadership Terhadap Komitmen Organisasi. E-Jurnal 
Manajemen, 7(9), 1-28.

Eliyana, A., \& Ma, S. (2019). Job satisfaction and organizational commitment effect in the transformational leadership towards employee performance. European Research on Management and Business Economics, 25(3), 144150. https://doi.org/10.1016/j.iedeen.2019.05.001

Gul, H., Usman, M., Liu, Y., Rehman, Z., \& Jebran, K. (2018). Does the effect of power distance moderate the relation between person environment fit and job satisfaction leading to job performance? Evidence from Afghanistan and Pakistan. Future Business Journal, 4(1), 68-83.

Hanaysha, J., \& Tahir, P. R. (2016). Examining The Effects Of Employee Empowerment, Teamwork, And Employee Training On Job Satisfaction. Social and Behavioral Sciences, 2(19), 272-282. https://doi.org/https://doi.org/10.1016/j.sbspro.2016.05.016

Indrawati, A. D., Honnor, S. I. ., \& Sutrisna Dewi, S. . (2017). Pengaruh Kesehatan dan Keselamatan Kerja pada Kepuasan Kerja dan Komitmen Organisasional. Matrik: Jurmal Manajemen, Strategi Bisnis Dan Kewirausahaan, 11(2), 105-155.

Jin, M. H., McDonald, B., \& Park, J. (2018). Does Public Service Motivation Matter in Public Higher Education Testing the Theories of PersonOrganization Fit and Organizational Commitment Through a Serial Multiple Mediation Model. American Review of Public Administration, 48(1), 82-97.

Khaola., P. ., \& Sebotsa, T. (2015). Person-organisation fit, Organisational commitment and organisational citizenship Behaviour. Danish Journal of Management and Business Science, 1(1), 67-74.

Kulachai, W. A., \& Amaraphibal. (2017). Developing a casual model of turnover intention of police officers in the eastern region of the Thailand. International Journal Of Arts \&Sceinces, 10(1), 473-486.

Nguyen, N., \& Borteyrou, X. (2016). Core self-evaluations as a mediator of the relationship between person-environment fit and job satisfaction among laboratory technicians. Personality and Individual Differences, 99(1), 89-9.

Ren., T., \& Hamann, D. J. (2015). Employee value congruence and job atitudes:the role of occupational status. Personnel Review, 1(1), 550-566.

Renyut, B. C., Modding, H. B., Bima, J., \& Sukmawati, S. (2017). The effect of organizational commitment, competence on Job satisfaction and employees performance in Maluku Governor's Office. Journal of Business and Management, 19(11), 18-29. https://doi.org/10.9790/487X-1911031829 
Risman, K. L., Rebecca., J., \& Erickson, J. (2016). The impact of personorganization fit on nurse job satisfaction and patient care quality. Applied Nursing Research, 3(1), 121-125.

Rosita, T., \& Yuniati, T. (2016). Pengaruh kepuasan kerja terhadap kinerja karyawan dengan komitmen organisasional sebagai variabel intervening. Jurnal Ilmu Dan Riset Manajemen, 5(1), 1-20.

Rumangkit., S., \& Maryati, S. (2017). Pengaruh Person-Organization Fit Terhadap Komitmen Organisasional Melalui Kepuasaan Kerja Pada Karyawan IBI (Informatics And Business Institute) Darmajaya. Jurnal Optimum, 7(2), 190-202.

Saputra, I. M. A., \& Wibawa, I. M. A. (2018). Pengaruh Kepuasan Kerja, Keadilan Organsasional, dan Pemberdayaan Karyawan Terhadap Komitmen Organisasional Karyawan. E-Jurnal Manajemen Unud, 7(6), 3201-3229.

Sari, \& Helmy, I. (2020). Pengaruh person-organization fit, job embeddedness dan religiusitas terhadap komitmen organisasional dengan kepuasan kerja sebagai variabel intervening. Jurnal Ilmiah Mahasiswa Manajemen, Bisnis Dan Akuntansi, 2(2), 197-213. 